Article

\title{
Evolutionary Game Analysis on Behavioral Strategies of Government and Residents in Municipal Household Waste Separation
}

\author{
Xueping $\mathrm{Wu}^{1}{ }^{1}$, Liping Zhang ${ }^{1, *}$, Jianhua Huang ${ }^{2}, \mathrm{Wei} \mathrm{Li}^{2}$, Yanhua Chen ${ }^{2}$ and Wenhai Qiu ${ }^{3}$ \\ 1 School of Economics and Trade, Fujian Jiangxia University, Fuzhou 350108, China; fjuxpwu@fjjxu.edu.cn \\ 2 School of Economics and Management, Fuzhou University, Fuzhou 350116, China; everam@fzu.edu.cn (J.H.); \\ liweifzu@163.com (W.L.); mingliuxi2004@163.com (Y.C.) \\ 3 School of Information Engineering, Fujian Business University, Fuzhou 350012, China; fzuqwh@163.com \\ * Correspondence: zlp201206@163.com
}

Citation: Wu, X.; Zhang, L.;

Huang, J.; Li, W.; Chen, Y.; Qiu, W.

Evolutionary Game Analysis on

Behavioral Strategies of Government and Residents in Municipal

Household Waste Separation.

Sustainability 2021, 13, 11421. https://

doi.org/10.3390/su132011421

Academic Editor: Antonis A. Zorpas

Received: 6 September 2021

Accepted: 12 October 2021

Published: 15 October 2021

Publisher's Note: MDPI stays neutral with regard to jurisdictional claims in published maps and institutional affiliations.

Copyright: (c) 2021 by the authors. Licensee MDPI, Basel, Switzerland. This article is an open access article distributed under the terms and conditions of the Creative Commons Attribution (CC BY) license (https:// creativecommons.org/licenses/by/ $4.0 /)$.

\begin{abstract}
Municipal household waste (MHW) separation is a fundamental way to achieve waste reduction and a recycling economy. This study takes the positions of government and residents in MHW separation as the research object, and aims to explore the change process and influencing factors of their decision-making behavior, which is of great significance to attract residents to participate in MHW separation and establish an effective MHW separation mechanism to solve MHW pollution. This paper firstly establishes an evolutionary game model between government and residents in MHW separation; secondly, the payoff matrix of the system is determined, and the replication dynamic equations under different constraints are calculated to obtain the evolutionary stability strategy of the system, and the stability conditions are analyzed; Finally, through numerical simulation, the decision-making behavior of MHW separation and its influencing factors are studied, and the rationality of the model is verified. The results show that: (1) In the process of MHW separation, residents often choose not to separate without government regulation; (2) Environmental fee rates and government effort have great impacts on residents' decision-making behavior; (3) The increase of penalty intensity can significantly drive residents to separate MHW; (4) The sensitivity of residents' behavior decision to subsidy coefficient is the lowest among all the variables, and the incentive effect of increasing subsidy coefficient is not obvious. The research results can not only provide theoretical guidance for policy makers to develop waste management policies, but also provide valuable insights for local communities to guide residents' MHW separation behavior.
\end{abstract}

Keywords: municipal household waste; waste separation; government stimulus; residents; evolutionary game theory

\section{Introduction}

The continuous growth of municipal household waste (MHW) production and the corresponding environmental pollution problems have seriously threatened the sustainable development of various countries, especially China [1]. Since 2004, the annual average growth rate of MHW generated by China has been $1.13 \%$, which has surpassed that of the United States and ranked first in the world [2]. The amount of MHW in China has increased from 161 million tons in 2013 to 236 million tons in 2019. MHW has become the main environmental by-products of urban development in China, while Beijing and Shanghai, which are densely populated, have become "garbage surrounded cities" [3]. According to statistics from the Ministry of Ecology and Environment of China, in 2019, the amount of MHW in Shanghai was 10.768 million tons, with an average of 29.5 thousand tons of MHW being produced per day. Shanghai has a population of 24.28 million and it has been said that each inhabitant produces $1.22 \mathrm{~kg}$ of MHW per day. Beijing's MHW production was only considered to be "reluctantly defeated" by Shanghai with a gap of 
65.6 thousand tons, ranking second in the country. Compared with international metropolises, Shanghai's MHW production is still relatively high, nearly twice that of Tokyo. In terms of per capita, it is also higher than Seoul, Tokyo, Singapore, New York, London, Paris and other major cities. However, China's MHW treatment system is far less perfected than those of other international metropolises.

China's existing MHW disposal methods are still mainly based on simple sanitary landfill and incineration, and the source separation of MHW, which plays a vital role in the waste recycling and utilization, is still in the preliminary implementation stage. Treating such a huge amount of waste by landfill and incineration will inevitably cause extensive environmental pollution, such as water and soil pollution and air pollution [3,4]. Source separation is an essential element of waste management to achieve high recycling rates [5]. In order to promote source separation, the Chinese government has also made a lot of efforts. For example, in 2017, the "Implementation Scheme for the Classification of Domestic Waste" was released, and 46 cities were identified as pilot cities. From 2019, cities across the country were to start separation in an all-round way. By the end of 2025, all cities will have established a waste separation system [6]. Nevertheless, there is a significant difference between the willingness of Chinese residents to classify MHW and the actual separation action [7]. The lack of cooperation and low participation of local residents is one of the reasons for the poor effect of the pilot [2,8]. Although these policies are mandatory, the final effect of these policies depends on the residents' consciousness of environmental protection. Residents tend to avoid risks and seek to maximize their own interests, which means that the implementation of separation policies cannot be guaranteed to be effective $[9,10]$. Understanding and guiding residents' behavior strategies of MHW separation can improve residents' participation and cooperation and promote the broad implementation of MHW sorting and recycling policies. Therefore, conducting research on the evolution of residents' MHW separation behavior is one of the important prerequisites for effectively promoting the reduction of MHW.

Ajzen [11] proposed planned behavior theory (TPB) on the basis of traditional rational behavior theory, emphasizing that individual behavior is not only affected by subjective attitudes and social plans but also affected by perceptual behavior control factors. Under the framework of TPB, the influence of social norms on residents' willingness to participate in separation and recycling has also been concerned by some scholars [12]. When residents participate in MHW separation and recycling, they will be affected by their neighbors or surrounding companions. In addition, under the framework of the norm activation model (NAM), personal norms (specifically a sense of personal moral obligation based on personal values) are considered to be an internal factor that promotes residents to participate in MHW sorting and recycling [13]. Although the model framework of TPB theory and the model framework of NAM provide good references for the research of residents' waste disposal behavior, there are still many shortcomings. The influencing factors considered by TPB and NAM are mainly the subjective factors of the individual, but the willingness of the individual's behavior to be transformed into actual action is also affected by other factors, such as government incentives and the availability of facilities [2]. The potential of most households to classify waste has not been stimulated, and it is far from enough to rely solely on value appeals [5]. The more appropriate and feasible way is to cultivate residents' MHW separation awareness and social responsibility through environmental protection education, supplemented by government policy stimulation. Moreover, although there are abundant studies on MHW, scholars pay more attention to the influencing factors of MHW separation behavior, and less on the strategic interaction between stakeholders in the process of MHW separation. From an economic point of view, MHW is a typically noncompetitive and nonexclusive public product. Garbage disposal usually results in such a situation: the government bears all the costs of garbage disposal, while other stakeholders benefit from it without producing costs, that is to say, "free riding" problem occurs [14]. The problem of free riding will hinder the government from choosing more advanced and expensive technologies or lead to the overuse of the provided services. 
Therefore, in the process of MHW governance, it is easy to cause "tragedy of the commons" and "prisoner's dilemma". The way to solve this problem is to let other stakeholders participate in the decision-making and implementation process. Thus, it is necessary to discuss from the process of stakeholder strategy interaction. Based on the hypothesis of bounded rational economic man and the reality of MHW separation in China, this paper aims to build an evolutionary game model of behavior strategy between government and residents, and theoretically explore the impact of behavioral changes of government and residents on MHW separation. In order to better achieve the research objectives, we focus on the following research issues:

(1) What are the conditions for the MHW separation strategy between government and residents to evolve into the maximization of environmental benefits?

(2) What stimulus mechanisms can the government choose to drive residents to separate MHW? Which mechanism works best?

To solve the above problems, this paper establishes an evolutionary game model of two-party players between the government and residents, determines the payoff matrix of the model, and calculates the replicator dynamics equation of each players. Then, the Jacobian matrix is used to obtain the conditions for the evolutionary stability strategy and the behavior strategy of government and residents to evolve into the maximization of environmental benefits. Finally, the rationality of the model is verified by numerical simulation, and the influence of the change of main parameters on the behavior evolution of the two players under different mechanisms is discussed. This paper mainly analyzes the strategic interaction between MHW separation actors from a theoretical perspective. Therefore, it contains few examples of actual measures, actions, and behaviors. The evolutionary game analysis can reflect the behavior evolution path and stability strategy of government and residents in MHW governance, which has a certain reference significance for better MHW management.

The rest of the study is structured as follows: Section 2 introduces the literature and points out the contributions of this paper. Section 3 describes these problems, puts forward basic assumptions. Section 4 establishes an evolutionary game model of strategic interaction between residents and government. Section 5 uses numerical simulation to analyze and compare the results obtained using parameter variations. Section 6 discusses the model and numerical simulations. Section 7 draws conclusions and offers suggestions for future actions.

\section{Literature Review}

Previous studies on MHW separation mainly focused on the principal factors affecting MHW separation and participation behavior, which provided support for decision makers/stakeholders to choose the best scheme. The key factors affecting the behavior of MHW separation and participation include internal factors such as attitude and knowledge (i.e., behavior attitude, environmental awareness, recycling and separation knowledge) [15-21], external factors such as social ties (i.e., families, friends, and neighborhoods) [5,22-26], facility convenience (i.e., separation facilities, distance to recycling, time costs, facilities) [2,27], economic and policy incentives (i.e., regulations, laws, economic profits, government subsidies) [2,28-31], technology (i.e., digital technology, bio-energy technology) [32,33], publicity and education [34], and individual social digital factors (i.e., gender, age, income, educational level, etc.) $[35,36]$. However, scholars mainly study the influence of different factors on the behavioral decision-making of a single subject from a static perspective, instead of exploring the influence of different factors on the behavioral decision-making of multiple subjects and the interaction between subjects from a dynamic perspective. In addition, previous studies have rarely explored the conditions for multiple entities to maximize the effect of MHW governance and the issues of making them sustainable and stable. From an economic perspective, all stakeholders are "economic men", and their behavior is based on maximizing their own interests. When external conditions change, they will also change their strategies to maximize their own interests. 
The interaction among multiple stakeholders is an interesting topic, which has an important impact on the real world [2]. Evolutionary game theory evolutionary game theory allows bounded rationality, which is closer to the decision-making rules of the real world. It provides an ideal tool for analyzing the impact of interaction on social dilemmas and environmental problems [37]. Chen and $\mathrm{Hu}$ [38] developed an evolutionary game theory model to examine the behavioral strategies of the manufacturers in response to various combinations of carbon taxes and subsidies. The results show that the behavior strategies of manufacturers are mainly affected by government policies. da Silva Rocha and Salomão [39] proposed an evolutionary game model to explore the interplay between corporate environmental compliance and enforcement promoted by the policy maker. Based on prospect theory and evolutionary game theory, Shen et al. [40] established an evolutionary game model between local governments and polluting enterprises in the Taihu Lake Basin of China and studied the decision-making behavior and influencing factors of watershed ecological compensation. In recent years, a few scholars have applied evolutionary game theory to waste classification and recycling. Shen et al. [41] used evolutionary game to analyze the recycling behavior of construction demolition waste between construction material contractors and manufacturers. Chen et al. [7] used evolutionary game to study the formation conditions of interpersonal cooperation mechanism in the process of MHW separation and found that individuals tend to have free riding behavior to maximize their own interests, which eventually leads to no one willing to take the initiative to classify garbage. Because the cooperation benefit is the essential factor to realize this relationship, the cooperation cost and government constraints determine the stability of the cooperation relationship. Wang et al. [42] proposed an evolutionary game model of three-party players composed of government, recyclers and consumers to explore the behavior strategies of multiple stakeholders in the e-waste recycling industry. Their results show that the government should play a leading role in the development of recycling industry.

To sum up, most of the previous studies are based on the static perspective to study the main factors that affect the separation and participation behavior of MHW, but few studies analyze the main factors and interaction mechanism of stakeholder decision-making from a dynamic perspective. In MHW governance, the game between government and residents is a repeated game process of random pairing and mutual learning, and its strategy adjustment process can be simulated by replication dynamic mechanism. Although some scholars have introduced evolutionary game theory to study the behavior decision-making of government and enterprises under the MHW scenario, they mainly focus on whether the enterprises adopt the recycling strategy, and do not specifically describe the characteristics and rules of MHW separation among residents. This paper attempts to fill these gaps.

The marginal contributions of this paper are as follows: (1) This paper discusses the evolution process and main influencing factors of decision-making behavior of government and residents in MHW separation from a dynamic perspective, so as to provide an important reference for policymakers of MHW separation in various countries. (2) From the micro point of view, this paper brings residents into the analysis framework of MHW separation, which is of great significance to enrich the theory of circular economy, effectively reduce MHW pollution and protect the living environment. (3) Based on the expected utility of different participants, an evolutionary game model of MHW separation between government and residents is established, which can effectively improve the scientificity of decision-making behavior analysis of MHW separation participants. The research results of this paper can provide a more perfect separation mechanism of MHW for the government, and then provide a basis for residents' decision-makers to participate in the separation of MHW.

\section{Problem Description and Assumption}

\subsection{Problem Description}

Residents, as the principal part of MHW generation in China, should be a main force of MHW separation. Separating MHW aims at reducing the amount of MHW, saving the 
cost of MHW disposal and bring potential benefits to the social environment. Compared with non-separation, separation can yield more benefits. However, MHW separation is an improvement of the original way of $\mathrm{MHW}$ disposal, which requires residents to invest a lot of time and energy. Residents seek to maximize their own interests, so the decision-making process of whether residents would separate MHW is uncertain. Effective MHW separation policies need to regulate, guide and adjust the separation behavior of the residents. Therefore, this is a game problem related to the decision-making of whether residents separate MHW or not and the policy-making of the government on MHW separation.

Government regulation has an important impact on whether residents separate municipal household waste or not. The government can manage it in four ways: subsidies, levy MHW disposal fee, fines and improve the intensity of government regulation. Subsidies refer to the subsidy of the input cost of residents' MHW separation in a certain proportion. MHW disposal fee refers to the waste disposal fee levied by the government on residents. Fines refer to the fines imposed by the government on residents who fail to separate MHW and/or produce excessive amounts of MHW.

\subsection{Model Assumption}

Evolutionary game theory originated in the field of biology, which regards organisms as a bounded rational man. They learn from each other, compete with each other and adapt to each other in the game. Its fundamental idea is that in a certain scale of game groups, the players are playing repeated game activities [43]. Evolutionary game theory replaces the assumption of the traditional game theory about the complete rationality of the subject with bounded rationality and learning ability. The bounded rationality determines that it is impossible for both sides of the gamer to find the optimal equilibrium point in every game. Evolutionary game theory uses a dynamic framework to analyze the process of system equilibrium and achieve equilibrium, so as to describe the development and change of the system more accurately. The core of the evolutionary game theory is the evolutionary stable strategy (ESS) and replicator dynamics [44]. Between them, the replicator dynamic equation is the most widely used dynamic equation of selection mechanism in evolutionary game theory.

This study assumes that the government and residents are bounded rational "economic person". When faced with incomplete information, their strategies are not optimal at first. Over time, through continuous learning and repeated attempts, they gradually find their own suitable strategies. Government and residents are two different groups. Residents are homogeneous, and their behavior will have an impact on the government's decision-making. Based on the above analysis, the following assumptions are made:

Assumption 1. In MHW separation, there are two strategies for government and residents. The government can select to regulate or not regulate the residents' behavior, and then its strategic space is (regulate, not regulate). The strategy space of residents is (separate, not separate). Government pays attention to both social benefits and their own economic benefits in policy-making. The key issue for residents in decision-making is to maximize economic benefits. The game between residents and government is repetitive and dynamic. They constantly adjust their strategies according to the changes of each other' strategies until they reach the ESS.

Assumption 2. It takes time for residents to learn the knowledge and methods of separation, and to separate and recycle $\mathrm{MHW}$ in daily life. The residents' cost of adapting a "separate" strategy is $C_{r}$. $\alpha$ denotes the efforts coefficient of the residents. If separated, residents acquire rewards $R_{r}^{2}$, and if not separated, residents obtain rewards $R_{r}^{1}$. Because the utilization rate of resources after separation of $\mathrm{MHW}$ can be significantly improved, then, $R_{r}^{2}>R_{r}^{1}$. If residents choose the "separate" strategy, it will produce positive social benefits $R_{g}$ and be owned by the government. Suppose the probability that residents separate $M H W$ is $x \quad(x \in[0,1])$, and the probability that residents do not separate MHW is $(1-x)$. 
Assumption 3. Assume the governmental cost of implementing regulation for residents is $C_{g}$, and the effort coefficient of government regulation is $\delta$. The residents who separate MHW can obtain government subsidies s, and the subsidy coefficient is $\mu$. The subsidies are based on residents' cost of separation, then $s<c$. The MHW disposal fees will be paid to the government by residents. They are obtained by multiplying the total amount of MHW $p$ by the corresponding fee rate. $\theta$ and $\beta$ are separated and non-separated applicable environmental fee rates, respectively $(\beta>\theta)$. Residents who do not separate may be punished with a penalty of $F . \gamma$ denotes the intensity of the punishment imposed by the government and the probability that the non-separation behavior of residents be discovered. If the government chooses "not regulate" and the residents choose "not separate", the excessive amount of MHW will cause public dissatisfaction and the loss of government credibility is $D$. When residents choose "not separate", the environmental loss is L. Assuming that the probability of government implementing regulation is $y(y \in[0,1])$, and the probability of government not implementing regulation is $(1-y)$.

The parameters and variables symbol descriptions are set and described in Table 1.

Table 1. Parameters and variables symbol descriptions.

\begin{tabular}{cc}
\hline Parameters & Descriptions \\
\hline$C_{r}$ & The residents' cost for MHW separation (e.g., time cost, economic cost) \\
$C_{q}$ & The government' cost for regulation \\
$R_{r}^{1}$ & The rewards of residents without MHW separation \\
$R_{r}^{2}$ & The rewards of residents with MHW separation \\
$R_{g}$ & The environmental values of MHW separation \\
$S$ & The subsidies for residents with MHW separation \\
$F$ & The penalties for residents without MHW separation \\
$D$ & The loss of government credibility without regulation \\
$L$ & The environmental loss of MHW non-separation \\
$\alpha$ & The effort coefficient of residents to separate MHW \\
$\beta$ & The environmental fee rate for residents without MHW separation \\
$\theta$ & The environmental fee rate for residents with MHW separation \\
$\delta$ & The effort coefficient of government to implement regulations \\
$\gamma$ & The penalty coefficient of the government \\
$\mu$ & The subsidy coefficient of the government \\
\hline Variables & Descriptions \\
\hline$x$ & The probability that residents separate MHW \\
$y$ & The probability that government implement the regulation \\
\hline
\end{tabular}

\section{Evolutionary Game Model}

\subsection{Game Model}

Based on the above relationship between the government and the residents and relevant literature [45], we can establish an evolutionary game model. The payoff matrix is shown in Table 2.

Table 2. Payoff Matrix of residents and government.

\begin{tabular}{cccc}
\hline \hline & Government & Regulate & Not Regulate \\
Residents & & $R_{r}^{2}-\alpha C_{r}+\mu S-\theta P, R_{g}-\delta C_{g}-\mu S+\theta P$ & $R_{r}^{2}-\alpha C, R_{g}$ \\
& Separate & $R_{r}^{1}-\beta P-\gamma F, \beta P+\gamma F-\delta C_{g}-L$ & $R_{r}^{1}-D-L$ \\
\hline
\end{tabular}

Then, residents' expected payoff for separating MHW is:

$$
U_{r 1}=y\left(R_{r}^{2}-\alpha C_{r}+\mu S-\theta P\right)+(1-y)\left(R_{r}^{2}-\alpha C\right)
$$


Residents' expected payoff for separating MHW is:

$$
U_{r 2}=y\left(R_{r}^{1}-\beta P-\gamma F\right)+(1-y) R_{r}^{1}
$$

Residents' average expected payoff is:

$$
\overline{U_{r}}=x U_{r 1}+(1-x) U_{r 2}
$$

The replicator dynamic system is dynamic differential equations describing the frequency of a particular strategy used in a population $[38,44,46]$. Residents' replicator dynamics equation of "separate" is therefore:

$$
\begin{aligned}
F(x) & =\frac{d x}{d t}=x\left(U_{r 1}-\overline{U_{r}}\right)=x(1-x)\left(U_{r 1}-U_{r 2}\right) \\
& =x(1-x)\left[(\mu S+\gamma F+\beta P-\theta P) y+\left(R_{r}^{2}-R_{r}^{1}-\alpha C_{r}\right)\right]
\end{aligned}
$$

Government' expected payoff for implementing the regulation is:

$$
U_{g 1}=x\left(R_{g}-\delta C_{g}-\mu S+\theta P\right)+(1-x)\left(\beta P+\gamma F-\delta C_{g}-L\right)
$$

Government' expected payoff for not implementing the regulation is:

$$
U_{g 2}=x R_{g}+(1-x)(-D-L)
$$

Government' average expected payoff is:

$$
\overline{U_{g}}=y U_{g 1}+(1-y) U_{g 2}
$$

Government' replicator dynamics equation of "regulate" is:

$$
\begin{aligned}
F(y) & =\frac{d y}{d t}=y\left(U_{g 1}-\overline{U_{g}}\right)=y(1-y)\left(U_{g 1}-U_{g 2}\right) \\
& =y(1-y)\left[-(\mu S+\gamma F+\beta P-\theta P+D) x+\left(\gamma F+\beta P-\delta C_{g}+D\right)\right]
\end{aligned}
$$

The replicator dynamic system is treated as the combination of Equations (4) and (8).

\subsection{Model Analysis}

Let $F(x)=0$, then $x=0, x=1$ and $y^{*}=-\left(R_{r}^{2}-R_{r}^{1}-\alpha C_{r}\right) /(\mu S+\gamma F+\beta P-\theta P)$.

Let $F(y)=0$, then $y=0, y=1$ and $x^{*}=\left(\gamma F+\beta P-\delta C_{g}+D\right) /(\mu S+\gamma F+\beta P-\theta P+D)$.

In this replicator dynamic system, there are five equilibrium points. The five equilibrium points are: $O(0,0), \quad A(0,1), \quad B(1,0), \quad C(1,1)$ and $D\left(x^{*}, y^{*}\right)$, which represent the five different strategies adopted by residents and government, respectively.

The five equilibrium points we get by replicator dynamic system are not necessarily the ESS. By analyzing the local stability of the Jacobian matrix, the stability of the equilibrium point can be obtained [46]. The functions of determinant $J($ det.J) and trace $J(\operatorname{tr} . J)$ of the Jacobian matrix are:

$$
\begin{aligned}
& J=\left[\begin{array}{rr}
\frac{d F(x)}{F x} & \frac{d F(x)}{d y} \\
\frac{d F(y)}{d x} & \frac{d F(y)}{d y}
\end{array}\right]=\left[\begin{array}{cc}
a & b \\
c & d
\end{array}\right] \\
&=\left[\begin{array}{cc}
(1-2 x)\left[(\mu S+\gamma F+\beta P-\theta P) y+\left(R_{r}^{2}-R_{r}^{1}-\alpha C_{r}\right)\right] & x(1-x)(\mu S+\gamma F+\beta P-\theta P) \\
y(1-y)[-(\mu S+\gamma F+\beta P-\theta P+D)] & (1-2 y)[-(\mu S+\gamma F+\beta P-\theta P+D)] x+\left(\gamma F+\beta P-\delta C_{g}+D\right)
\end{array}\right] \\
& \text { det. } J=\frac{d F(x)}{d x} \cdot \frac{d F(y)}{d y}-\frac{d F(x)}{d y} \cdot \frac{d F(y)}{d x}=a d-b c \\
& \operatorname{tr} . J=\frac{d F(x)}{d x}+\frac{d F(y)}{d y}=a+b
\end{aligned}
$$

Let $\Delta R=R_{r}^{2}-R_{r}^{1}$, where $\Delta R$ represents the increase in earnings of residents after separating MHW. According to Assumption 2, we have $\Delta R>0 . \alpha C_{r}-\mu S$ means the actual 
input of residents to separate MHW. $\theta P$ and $\beta P$ respectively indicate the MHW disposal fee paid by residents with MHW separation and non-separation under the government ${ }^{\prime}$ environmental regulations. According to Assumption 3, $\beta P>\theta P$. The expression $\Delta R=\alpha C_{r}$ $+\mu S+\gamma F+\beta P-\theta P$ can be regarded as the earnings gap of residents between the two strategies of separation and non-separation when the government chooses a regulation strategy. If the value is positive, it means that separating MHW can obtain provide more benefits under the government' environmental regulation. $\theta P-\mu S-\delta C_{g}$ indicates the earnings gap of government between the two strategies of regulation and non-regulation when residents separate MHW. $\gamma F+\beta P+D-\delta C_{g}$ indicates that the earnings gap of government between the two strategies of regulation and non-regulation when residents do not separate MHW.

The local stability analysis depends on the symbols of det.J and tr.J. Only when the symbol of det.J is positive and the symbol of tr.J is negative, can the equilibrium point be stable. To simplify the issue, we set $M=\Delta R-\alpha C_{r}$ and $N=\gamma F+\beta P+D-\delta C_{g}$, $K=\mu S+\gamma F+\beta P-\theta P, V=\theta P-\mu S-\delta C_{g}$. Table 3 presents the simplified det.J and tr.J of each local equilibrium point. Based on the local stability analysis method of Jacobian matrix, this study analyses the local stability of the five equilibrium points obtained above and divides them into the following propositions. Table 4 presents the local stability analysis of the equilibrium point and provides six scenarios in this game.

Table 3. Simplified det.J and tr.J of local equilibrium points.

\begin{tabular}{ccc}
\hline Equilibrium Point & det.J & tr.J \\
\hline$O(0,0)$ & $M N$ & $M+N$ \\
$A(0,1)$ & $-N(M+K)$ & $M-V-D$ \\
$B(1,0)$ & $-M V$ & $V-M$ \\
$C(1,1)$ & $V(M+K)$ & $-(M+N+D)$ \\
$D\left(x^{*}, y^{*}\right)$ & $-[M N V(M+K)] /[K(\mathrm{~K}+D)]$ & 0 \\
\hline
\end{tabular}

Table 4. Local Stability Analysis of Equilibrium Point.

\begin{tabular}{|c|c|c|c|c|c|}
\hline Scenario & Assumption & Equilibrium Point & Symbol of det.J & Symbol of tr.J & Local Stability \\
\hline \multirow{5}{*}{ Scenario 1} & $M<0$ & $O(0,0)$ & + & - & ESS \\
\hline & $M+K<0$ & $A(0,1)$ & - & - & Saddle point \\
\hline & $N<0$ & $B(1,0)$ & + & + & Instability point \\
\hline & $V>0$ & $C(1,1)$ & - & $\mathrm{N}$ & Saddle point \\
\hline & & $D\left(x^{*}, y^{*}\right)$ & - & 0 & Saddle point \\
\hline \multirow{5}{*}{ Scenario 2} & $M<0$ & $O(0,0)$ & + & - & ESS \\
\hline & $M+K<0$ & $A(0,1)$ & - & $\mathrm{N}$ & Saddle point \\
\hline & $N<0$ & $B(1,0)$ & - & $\mathrm{N}$ & Saddle point \\
\hline & $V<0$ & $C(1,1)$ & + & $\mathrm{N}$ & Saddle point \\
\hline & & $D\left(x^{*}, y^{*}\right)$ & + & 0 & Saddle point \\
\hline \multirow{5}{*}{ Scenario 3} & $M<0$ & $O(0,0)$ & - & $\mathrm{N}$ & Saddle point \\
\hline & $M+K<0$ & $A(0,1)$ & + & - & ESS \\
\hline & $N>0$ & $B(1,0)$ & + & + & Instability point \\
\hline & $V>0$ & $C(1,1)$ & - & $\mathrm{N}$ & Saddle point \\
\hline & & $D\left(x^{*}, y^{*}\right)$ & + & 0 & Saddle point \\
\hline \multirow{5}{*}{ Scenario 4} & & $O(0,0)$ & + & + & Instability point \\
\hline & $M>0$ & $A(0,1)$ & - & $\mathrm{N}$ & Saddle point \\
\hline & $N>0$ & $B(1,0)$ & + & - & ESS \\
\hline & $V<0$ & $C(1,1)$ & - & - & Saddle point \\
\hline & & $D\left(x^{*}, y^{*}\right)$ & - & 0 & Saddle point \\
\hline
\end{tabular}


Table 4. Cont.

\begin{tabular}{|c|c|c|c|c|c|}
\hline Scenario & Assumption & Equilibrium Point & Symbol of det.J & Symbol of tr.J & Local Stability \\
\hline \multirow{5}{*}{ Scenario 5} & & $O(0,0)$ & - & - & Saddle point \\
\hline & $M>0$ & $A(0,1)$ & + & $\mathrm{N}$ & Saddle point \\
\hline & $N<0$ & $B(1,0)$ & + & - & ESS \\
\hline & $V<0$ & $C(1,1)$ & - & $\mathrm{N}$ & Saddle point \\
\hline & & $D\left(x^{*}, y^{*}\right)$ & + & 0 & Saddle point \\
\hline \multirow{5}{*}{ Scenario 6} & $M>0$ & $O(0,0)$ & + & + & Instability point \\
\hline & $M+K>0$ & $A(0,1)$ & - & $\mathrm{N}$ & Saddle point \\
\hline & $N>0$ & $B(1,0)$ & - & $\mathrm{N}$ & Saddle point \\
\hline & $V>0$ & $C(1,1)$ & + & - & ESS \\
\hline & & $D\left(x^{*}, y^{*}\right)$ & + & 0 & Saddle point \\
\hline \multirow{5}{*}{ Scenario 7} & $M<0$ & $O(0,0)$ & - & $\mathrm{N}$ & Saddle point \\
\hline & $M+K>0$ & $A(0,1)$ & - & - & Saddle point \\
\hline & $N>0$ & $B(1,0)$ & + & + & Instability point \\
\hline & $V>0$ & $C(1,1)$ & + & $\mathrm{N}$ & Saddle point \\
\hline & & $D\left(x^{*}, y^{*}\right)$ & - & 0 & Saddle point \\
\hline
\end{tabular}

Proposition 1. When $M<0$ and $N>0, M+K<0$, then $O(0,0)$ is an ESS of the MHW separation system. The evolutionary stable strategy is (Not separate, Not regulate). This steady state is not conducive to MHW separation, indicating that the government and residents are in a negative state of inaction at the same time.

Proof. From Scenario 1 and Scenario 2 of Table 4, we can see that whether $V>0$ or $V<0$, as long as it meets the condition $M<0, N<0, M+K<0$, all the evolutionary stable strategies are (not separate, not regulate). In the MHW separation system, if $M<0$, the earnings $\Delta R$ of residents' MHW separation is too small, until it is less than the input $\alpha C_{r}$, residents will choose the "not separate" strategy for economic benefit. At this time, if $N<0$, the sum of MHW disposal fee $\beta P$, fines $\gamma \mathrm{F}$ and credibility $D$ obtained by the government with the "regulate" strategy cannot offset the regulation cost $\delta C_{g}$, so the government will choose the "not regulate" strategy, and the MHW separation system will eventually evolve to a stable point $O(0,0)$.

Proposition 2. When $M<0$ and $N>0, M+K<0, V>0$, then $A(0,1)$ is an ESS of the MHW separation system. The evolutionary stable strategy is (not separate, regulate). This situation is the worst of the four stable-state, because residents still choose the "not separate" strategy under the government environmental regulation, which is the state of ineffective government regulation and residents' passive resistance.

Proof. As shown in Scenario 3 of Table 4 , we can see that if $M+K<0$, under the government' environmental regulation, the earnings $\Delta R+\gamma F+\beta P-\theta P$ of residents between "separate" and "not separate" is less than the actual input $\alpha C_{r}-\mu S$, residents would rather be punished and pay more MHW disposal fees than choose the "separate" strategy. Even when there are residents who have chosen to separate in the system, they will eventually abandon the "separate" strategy in pursuit of maximizing their interests. In this situation, the government's environmental regulation is ineffective for residents.

Proposition 3. When $M>0$ and $V<0$ then $B(1,0)$ is an ESS of the MHW separation system. The evolutionary stable strategy is (separate, not regulate). This situation is the "ideal state" of MHW separation system, but because of the high cost of MHW separation, it is difficult to achieve this state in our country at present.

Proof. As shown in Scenario 4 and Scenario 5 of Table 4, we can see that whether $N>0$ or $N<0$, as long as it meets $M>0, V<0$, all the evolutionary stable strategies 
are (separate, not regulate). When $M>0$ the earnings $\Delta R$ of MHW separation is greater than the cost $\alpha C_{r}$, so the residents will get more economic benefits after choosing the separation strategy. Without government regulation, the residents will choose the "separate" strategy spontaneously. In the process of evolution, even if there is an unstable state in which residents do not separate MHW, they will eventually choose to separate MHW because of the principle of maximizing their interests. At this time, if $V<0$, the government's regulatory costs are greater than its benefits, the final system will evolve to a stable state of $x=1, y=0$, that is, residents separate MHW, the government do not regulate. This is an ideal state for residents to separate MHW spontaneously, but because China is in the initial stage of MHW separation pilot, its management costs are high and the policy is not perfect, so it is difficult to achieve at this stage.

Proposition 4. When $M>0, V>0, N>0, M+K>0$ then $C(1,1)$ is an ESS of the MHW separation system. The evolutionary stable strategy is (separate, regulate). This situation is a relatively easy situation to achieve in the short term, which is conducive to MHW separation.

Proof. As shown in Scenario 6 of Table 4, if $M>0$, Since the earnings increase $\Delta R$ of residents after MHW separation is greater than that of input $\alpha C_{r}$, residents will choose the "separate" strategy spontaneously. If $V>0$, the earnings of government $\theta P$ is greater than total input $\mu S+\delta C_{g}$, so the government can use its net earnings to build infrastructure and so the government will tend to choose "regulate" strategy. When $M+K>0$ and $V>0$ are satisfied, under the government environmental regulation, residents who choose to separate will get more earnings $\Delta R+\gamma F+\beta P-\theta P$ than those who have not separated $\mathrm{MHW}$, and the earnings are greater than the actual input $\alpha C_{r}-\mu S$, then residents will choose the "separate" strategy in order to obtain subsidies or reduce penalties in the long run.

Proposition 5. When $M<0, V>0, N>0, M+K>0$ then the MHW separation system has no ESS and shows an infinite closed loop. This situation is relatively in line with the reality of China, and it is a situation worthy of further discussion.

Proof. As shown in Scenario 7, there is no ESS. If $M<0$, the earnings $\Delta R$ of residents after MHW separation is less than that of input $\alpha C_{r}$, therefore residents are reluctant to separate MHW. However, residents can still be encouraged to choose the "separate" strategy through the government's environmental regulation policy to promote MHW separation. The government can achieve this by appropriately adjusting MHW treatment fee rate $\beta$, input subsidy intensity $\mu$, penalty intensity $\gamma$ and regulation effort $\delta$. If the government does not regulate and $\Delta R<\alpha C_{r}$, it will return to the state of inaction of both government and residents described in Scenario 1.

\section{Simulation Analysis}

Due to the complexity of the resultant equations and the large number of parameters in the model, we applied numerical examples to more intuitively analyze the impact of varying the environmental fee rate $\beta$, subsidy coefficient $\mu$, penalty intensity $\gamma$ and effort coefficient of government regulation $\delta$. Moreover, we explain how these four main parameters affect the optimal strategy of the government and residents. The Matlab 2016b software is adopted to analyze the optimal strategy. The results have been outlined in the following figures, where, $R_{r}^{2}=55, R_{r}^{1}=35, \alpha=0.3, C_{r}=50, \mu=0.3, S=15, \beta=106, \theta=84.48$, $P=0.3409, \gamma=0.2, F=50, \delta=0.2, C_{g}=100, D=50$.

\subsection{Environmental Fee Rate}

Figure 1 shows the evolution paths of the system when the environmental fee rate $\beta$ values are $1,10,50,90$ and 120 , respectively. When $\beta=1,10,50$, the evolutionary stable point of the system is $(1,0)$ (see Figure $1 \mathrm{a}$ ). When $\beta=90$ and $\beta=120,(1,1)$ is the 
evolutionary stable strategy of the system. All residents are willing to choose to separate MHW under the government environmental regulation. The adjustment of $\beta$ value has a great impact on residents' decision-making (see Figure 1b). Within a certain range, the larger the $\beta$ value is, the faster the residents evolve to the stable state of choosing separation MHW strategy. Because when $M+K>0$ is satisfied, the larger the $\beta$ value is, the larger the MHW disposal fee saved, and the greater the incentive effect for residents to choose separating MHW will be.

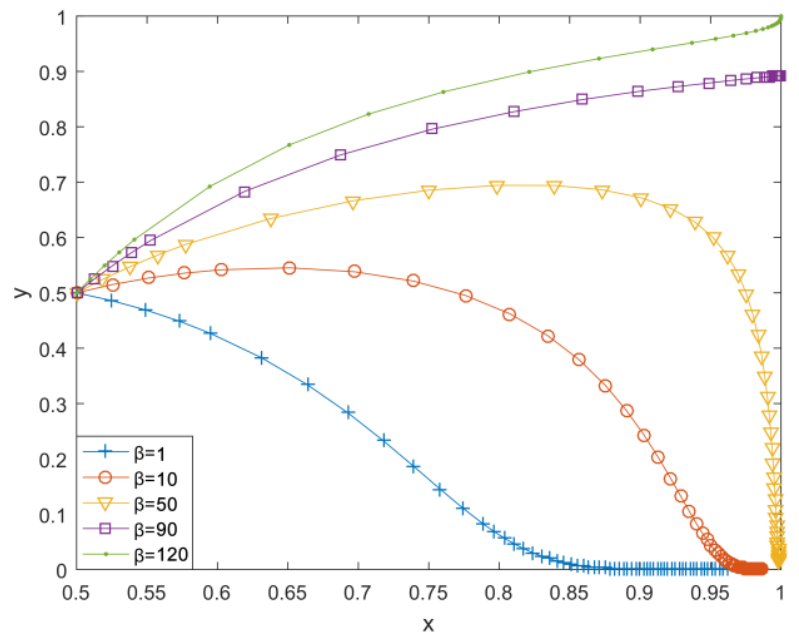

(a)

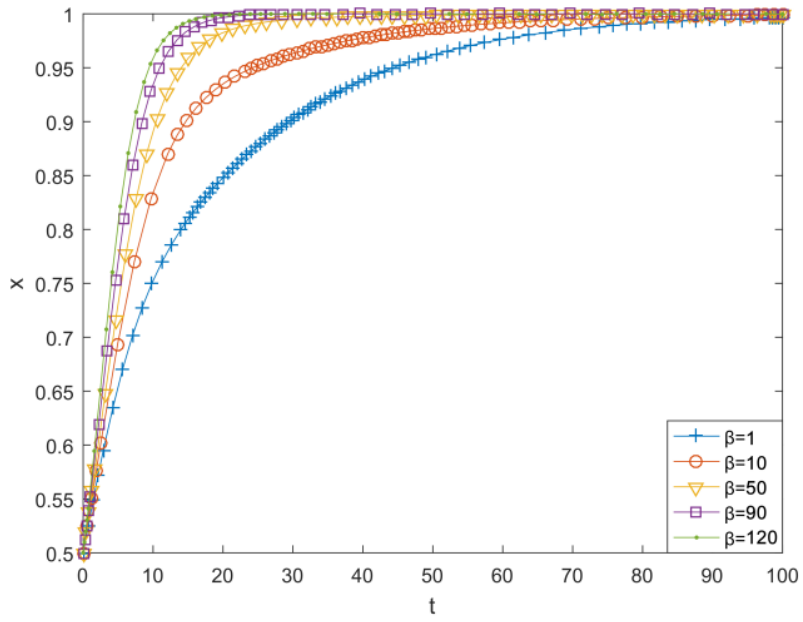

(b)

Figure 1. Evolution path of the system and residents' behavioral strategy with different environmental fee rate $\beta$ values. (a) Evolution path of government and residents' behavioral strategy with different $\beta$ values; (b) Evolution path of residents' behavioral strategy with different $\beta$ values.

\subsection{Subsidy Intensity}

Figure 2 shows the evolution paths of the system when the subsidy coefficient $\mu$ values are $0.5,1.0,1.5,2.0,2.5$, respectively. As shown in Figure $2 \mathrm{a}$, when $\mu=0.5$, the system evolves to $(1,1)$. The subsidy policy plays a positive incentive role in the MHW separation and promotes the evolution of MHW separation system to the stable state that all residents separate MHW under government regulation. When $\mu=1.0,1.5,2.0,2.5$, the system evolves to $(1,0)$. The increase of $\mu$ value, the evolution speed of the government towards the stable point gradually slows down, and eventually the government will abandon regulation. As shown in Figure $2 \mathrm{~b}$, with the change of $\mu$ value, the evolution curve almost coincides, indicating that the adjustment of $\mu$ value has less influence on residents' decision-making.

\subsection{Penalty Intensity}

Figure 3 shows the impact of the government's penalty intensity $\gamma$ on system evolution when $\gamma$ is $0.1,0.3,0.5,0.7$ and 0.9, respectively. From Figure 3a, we can see that MHW separation system is less sensitive to $\gamma$, and the evolution speed of the system slows down slightly with the increase of $\gamma$ value. However, increasing the penalty intensity of the government has a positive incentive for residents to separate MHW. As shown in Figure $3 b$, with the increase of $\gamma$ value, the evolution speed of residents' choice of separation is gradually accelerated. This is because once the government strengthens the punishment, the probability that residents will be punished for evading the regulation is increased. When making decisions, residents perceive that the value of the fine increases. As the risk of evading government regulation increases, residents prefer to choose separation strategy. 


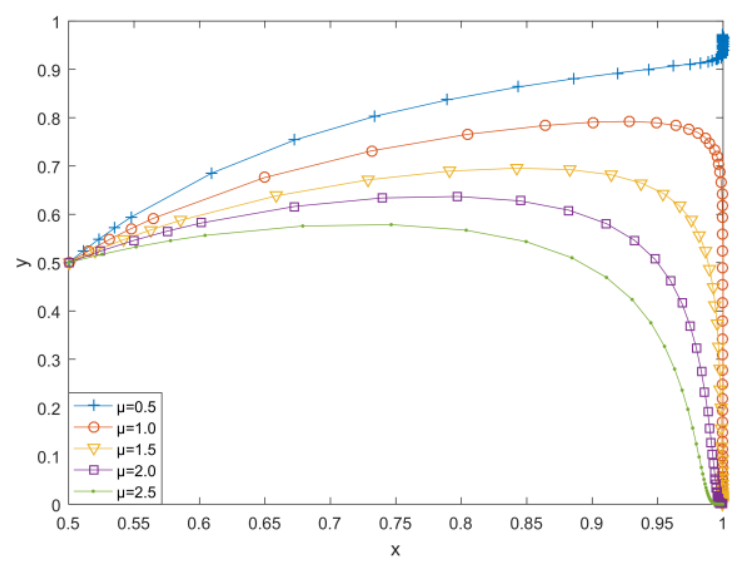

(a)

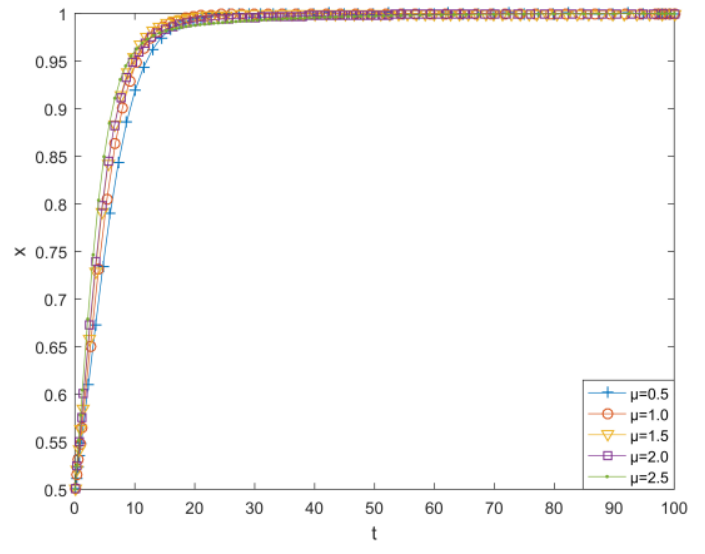

(b)

Figure 2. Evolution path of the system and residents' behavioral strategy with different subsidy coefficient $\mu$ values. (a) Evolution path of government and residents' behavioral strategy with different $\mu$ values; (b) Evolution path of residents' behavioral strategy with different $\mu$ values.

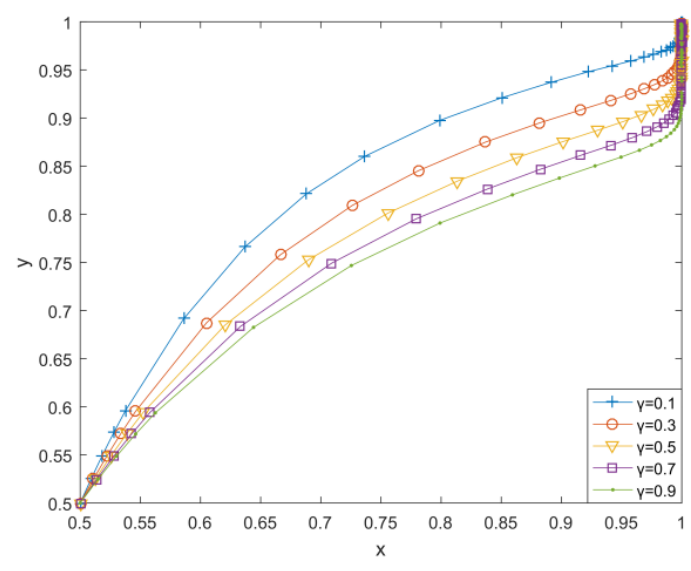

(a)

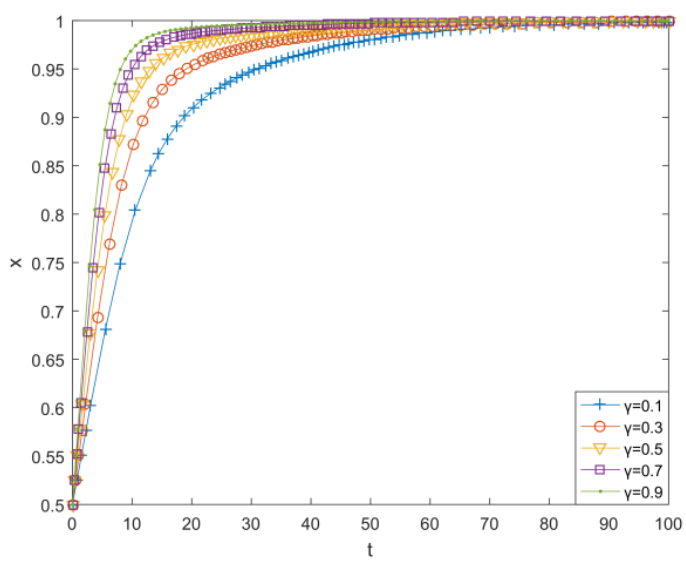

(b)

Figure 3. Evolution path of the system and residents' behavioral strategy with different penalty coefficient $\gamma$ values. (a) Evolution path of government and residents' behavioral strategy with different $\gamma$ values; (b) Evolution path of residents' behavioral strategy with different $\gamma$ values.

\subsection{Government Effort}

Figure 4 shows the evolution of the system when the effort coefficient of government regulation $\delta$ is $0.1,0.2,0.3,0.4$ and 0.50 , respectively. From Figure $4 a$, we can see that the government is also a rational economic man in MHW separation. It should take into account both social interests and its own interests. When $\delta=0.1$ and $\delta=0.2$, the government will choose the regulation strategy. However, with the strengthening of the government's efforts, the government needs to invest more manpower and material resources and other costs. When $\delta$ exceeds the threshold, the government will choose the non-regulation strategy. This is the ideal state of MHW separation. Residents spontaneously separate MHW, and the government does not need to invest a lot of manpower and material resources to regulate it. As shown in Figure $4 \mathrm{~b}$, the effort coefficient of government regulation has a positive incentive effect on residents' choice to separate MHW, but with the increase of $\delta$ value, the speed of residents' evolution towards the stable strategy of separation gradually slows down. 


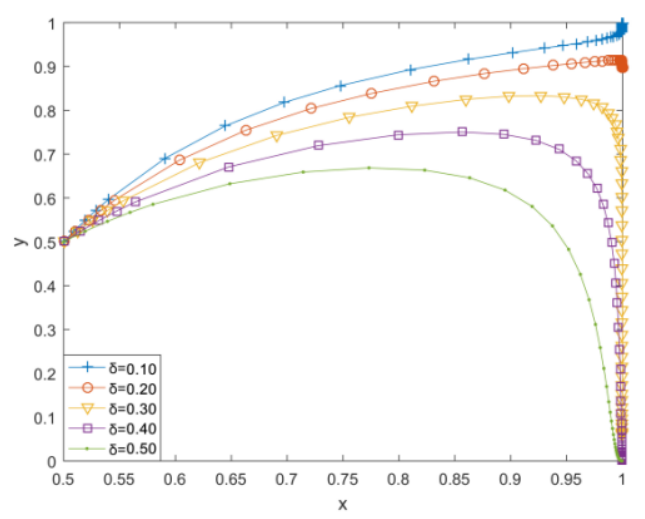

(a)

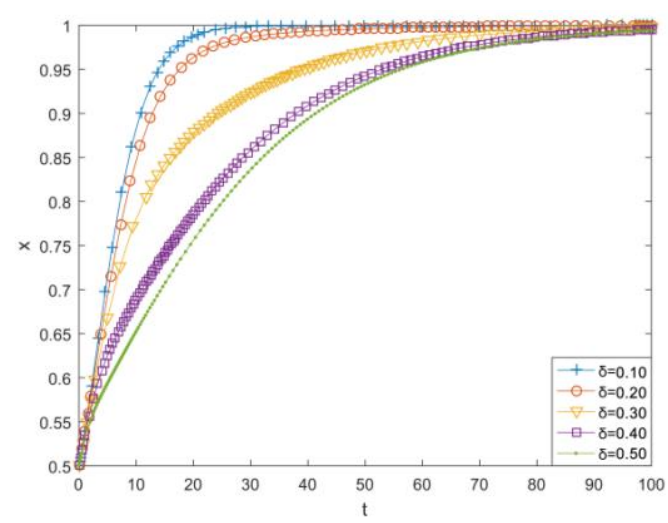

(b)

Figure 4. Evolution path of the system and residents' behavioral strategy with different effort coefficient of government $\delta$ values. (a) Evolution path of government and residents' behavioral strategy with different $\delta$ values; (b) Evolution path of residents' behavioral strategy with different $\delta$ values.

\section{Discussion}

\subsection{Condition of "Ideal State"}

In MHW separation model, the evolutionary behaviors between government and residents considering different constraints are different. Among all kinds of behavioral strategies, the most ideal state is that the government chooses "not regulate" and the residents choose "separate". The government does not regulate the separation of MHW, the residents will separate MHW. The stability of this state is determined by the cost of residents and the reward and punishment mechanism of the government. The conditions for residents to choose the separation strategy spontaneously are the earnings of residents' MHW separation is greater than the input $\left(\Delta R>\alpha C_{r}\right)$, but this "ideal state" is difficult to achieve at present. The government needs to implement the regulation policy to encourage residents to choose the separation strategy. At this time, only the earnings difference of the separation and non-separation strategy $\Delta R+\gamma F+\beta P-\theta P$ is greater than the actual input $\alpha C_{r}-\mu S$ of residents' separation, and the sum of the regulation cost $\alpha C_{g}$ and the subsidy $\mu S$ is less than MHW disposal fee $\theta P$, will the MHW separation system evolve into a stable state in which all residents choose the separation strategy under the regulation of government.

\subsection{Environmental Fee Rate}

According to the simulation results in Section 5.1, for residents, increasing the environmental rate has a greater impact on them. According to the theory of limited economic man, the residents are the pursuers of maximizing their personal interests, and they want to avoid government regulation. Therefore, increasing the environmental tax rate can accelerate the residents to reach a stable state. At present, governments all over the world adopt the way of levying environmental fees/taxes to limit the polluters' pollution behavior. This kind of legal enforcement helps to improve the residents' environmental awareness and promote them to reduce the amount of MHW. For the government, its main interest is to obtain the maximum benefits, including economic benefits, ecological benefits and social benefits. In the past, all countries in the world focused on economic interests, but their awareness of environmental protection was weak. At this time, even if the environmental rate increases, the government will still tend to pursue economic development and ignore environmental protection, so it will tend to stabilize at 0 . However, with the emergence of environmental pollution and the improvement of people's awareness of the importance of the environment, governments have to pay attention to environmental benefits. Thus, the government gradually changes from stable state 0 to stable state 1 . The research of Meng et al. [28] shows that specific charging policies can improve the performance of 
residents' separation behavior and are a more effective way to reduce MHW and increase the collection rate of recyclable resources in life, which confirms the point of this paper. In fact, in practice, levying environmental fees/taxes policies has been promoted. For example, in some communities, if people do not separate MHW, they need to pay MHW fees [20].

\subsection{Subsidy Intensity}

From the simulation results in Section 5.2, it can be seen that the subsidy coefficient, as a reward for separating MHW from residents, has a weak impact on residents. No matter how big the subsidy coefficient is, its incentive effect on residents is not obvious. In addition, the effect of subsidy coefficient on the government is only obvious when the coefficient is low. Therefore, the subsidy coefficient is not the most important factor to drive residents to separate MHW. This is because when residents compare the subsidy coefficient with the original profit before separation, they find that the profit before separation will be significantly greater than the subsidy coefficient they get. Therefore, residents are less sensitive to the subsidy coefficient. At the same time, increasing the subsidy coefficient cannot promote the separation of residents from MHW, but it needs to be kept in a stable state. But for the government, the allocation of subsidy coefficient is a certain expenditure. When the subsidy coefficient is low, the government is willing to reward the residents to separate MHW. However, when the subsidy coefficient is high, the increase of the subsidy coefficient will have a greater impact on the choice of its strategy. With the increase of the subsidy coefficient, the government has experienced the transition process from paying to not paying subsidies, and the time to reach a stable state is gradually shortened. This implies that the higher the subsidy, the greater the loss of government. This is consistent with Tang et al.'s research results [47].

\subsection{Penalty Intensity}

From the simulation results in Section 5.3, it can be seen that the penalty coefficient, as a punishment for residents not separating MHW, has a greater impact. No matter how large the penalty coefficient is, its negative incentive effect is very obvious. It shows that the MHW separation and recycling system should not only establish a reward mechanism, but also a punishment mechanism. The role of the punishment mechanism in the early stage of the implementation of the MHW separation policy is greater than the reward mechanism. For residents, the increase in the penalty coefficient indicates that the cost of violations by residents has risen, and if MHW is not separated, more fines will be paid. Out of the consideration of seeking advantages and avoiding disadvantages, residents will choose to separate MHW, so they are more sensitive to the penalty coefficient. This is consistent with the findings of Acuff and Kaffine [48], Xu et al. [49] in demonstrating the effectiveness of different penalty recycling policies. For the government, the increase in the penalty coefficient means that on the one hand, the government needs to strengthen its supervisory capabilities, and on the other hand, the government can obtain fines for not implementing the separation of MHW. Therefore, the government will always choose punishment measures, but the government is less sensitive to the punishment coefficient. This finding is not difficult to be confirmed in reality. In some cities where MHW separation is mandatory, such as Shanghai, Xiamen and Shenzhen, punishment measures have been promoted. For example, in Shanghai, the first time fine for not sorting garbage for is between 50 and 100 yuan, and the fine for not sorting garbage for the second time is between 100 and 200 yuan. The fines in Xiamen and Shenzhen can be as high as 1000 yuan [20].

\subsection{Government Effort}

According to Section 4.2, we can find that if the government does not regulate, residents will choose the strategy of not separating the MHW, and then dump the unseparated garbage into the landfill, which is one of the reasons for MHW pollution. This shows that 
the government's MHW regulation is conducive to the implementation of MHW separation and recycling policy and the harmlessness, reduction and resource utilization of MHW. In addition to government participation, the degree of government regulation efforts also plays an important role. The degree of government regulation effort is a sign of whether the government can effectively supervise the behavior of residents separating MHW. The simulation results in Section 5.4 show that, for residents, the increase of government regulation efforts indicates that the government is more likely to find out whether residents separate MHW and reduce the possibility of residents escaping punishment. This finding is consistent with the empirical research results of Wan et al. [50]. They investigated the "carrot and stick" policy measures implemented by the Hong Kong government, that is, incentives and penalties for waste separation and recycling. It turns out that residents will better perceive the constraints of the policies, which helps to promote waste separation and recycling. For the government, the improvement of regulatory efforts means that the government needs to invest more in the establishment of MHW separation and recycling equipment, the cost of relevant management personnel and regulatory system. In order to reduce expenditure, the improvement of government regulation efforts will significantly reduce the enthusiasm of government rules. This is empirically verified by scholars, such as Mo et al. [51], Wang et al. [52].

\subsection{Limitation and Future Work}

This study has some limitations, which are determined by the basic nature of the evolutionary game. Firstly, there may be some uncertain problems in the process of implementing the differential charging, punishment, and subsidy mechanisms, involving further influencing factors, such as socio-culture [26,53], law and institution [2,30], technology [33], environmental awareness [34], etc. It is very difficult for the government to elaborate on each treatment fee, fine or subsidy because of the limited time and energy. Similarly, improving the ability of government regulation is an effective way to address this problem. Secondly, the probability of residents separating MSW does not depend entirely on the government's MSW treatment fees, fines or subsidy mechanism. Our research is conducted on the premise that only the residents and government participate in the game. Thirdly, the model cannot consider the differences between residents in real life, nor can it analyze the impact of all real-life impacts on participants in the mechanism. In addition, another limitation of this study is that it only discusses the issue of MHW separation in daily life, without considering the abnormal state of COVID-19. Future research will be carried out from the following aspects: (1) Considering the heterogeneity of residents in MSW management, the game among different residents will be studied; (2) the tripartite game among residents, incinerators, and governments will be studied; (3) considering social norms and cultural factors, the effects of cultural consumption influence on MHW separation and recycling will be studied; (4) the impact of strategies proposed by several countries during the pandemic on MHW separation.

\section{Conclusions and Policy Implications}

MHW separation can increase the resource value and economic value of waste, reduce MHW processing volume, processing costs, and the consumption of land resources, which is of great significance to sustainable development. Therefore, MHW separation is an important way to achieve waste reduction and recycling economy and avoid "garbage siege". In the past, research on the separation of MHW was mainly carried out from the level of residents. Reviewing the research on MHW separation, it is found that the existing literature is mainly carried out from the resident level based on the static perspective and lacks the analysis of the main factors and interaction mechanism of stakeholder decision-making from the dynamic perspective. In addition, previous studies have rarely involved exploring the conditions for multiple entities to maximize MHW governance benefits and make it sustainable and stable. MHW management is a continuing challenge, and more research is needed to determine the factors that affect residents' MHW sepa- 
ration behavior and explore the conditions for residents to continue and stably separate MHW. Therefore, taking the government and residents as the research object, this paper first establishes the evolutionary game model between government and residents, and discusses the change process and main influencing factors of government and residents decision-making behavior in the separation of MHW from a dynamic perspective; then, the Jacobian matrix is used to obtain the evolutionary stability strategies and the conditions for the government and residents to maximize environmental benefits; finally, numerical simulation is used to verify the rationality of the model, and the effects of changes in main parameters under different mechanisms on the evolution of participants' behavior are discussed. The main contribution of this article is to incorporate residents into the analysis framework of government MHW management from a micro level. Based on the expected utility of different participants, an evolutionary game model between government and residents in MHW separation is constructed, which effectively improves the scientificity of decision-making behavior analysis of MHW separation participants and enriches the theory of circular economy. The main conclusions of this article are as follows:

(1) In the game between the government and residents, due to the high opportunity cost of residents and lack of motivation to separate MHW, in the absence of government regulation, residents often choose not to separate;

(2) The increase in environmental fee rates has a significant impact on residents' decisionmaking behavior;

(3) The increase in subsidy intensity has a weak impact on residents' decision-making behavior, and its incentive effect is not obvious;

(4) The increase in government regulation efforts has a greater impact on residents, but it is interesting that the increase in government regulation efforts will significantly reduce the enthusiasm of government regulation;

(5) Surprisingly, residents are most sensitive to the increase in the penalty coefficient. The increase in the penalty coefficient can significantly promote residents to separate MHW;

(6) Among the three reward and punishment mechanisms, the punishment mechanism can stimulate residents to separate MHW more than the reward mechanism.

A preliminary implication of this study is that residents may not be willing to separate MHW without government regulation. However, when the government provides a reward and punishment mechanism for MHW separation, residents may be willing to separate MHW. Bearing this in mind, it would be reasonable for policymakers to combine different and complementary policy tools. The results clearly show the strengths and weaknesses of each stimulus. Therefore, decision-makers can recognize noteworthy issues in the implementation stage, so as to improve residents' enthusiasm for separating MHW and the sustainability of MHW management. In fact, combining environmental fee/tax with a reward-penalty mechanism will produce beneficial synergies. Thus, policymakers should continue to promote the implementation of the MHW treatment fee/tax mechanism to reflect the principle of "producer pays" and promote MHW reduction, encourage localities to innovate MHW treatment fee/tax charging models and increase collection rates, establish a dynamic adjustment mechanism for MHW treatment charging standard. At the same time, establish a benign MHW separation reward-penalty mechanism. On the one hand, the government should realize that simply granting subsidies may be inefficient. Hence, it is necessary to innovate the reward-penalty mechanism of MHW separation, especially in terms of subsidies. The government may consider adopting material subsidies, deposit refunds, environmental fee/tax concessions, etc. On the other hand, it is necessary to punish the non-compliance of MHW separation in the initial stage. The government should innovate the punishment measures for residents who do not follow the regulations for MHW disposal. In addition to fines, it can also consider associating the MHW separation with the credit system.

The research results also show that the participation of two parties is needed to improve the effectiveness of MHW separation. The operational efficiency of MHW management depends on the active participation of the government and residents [54]. The 
circulation of resources is a challenge that cannot be postponed, and the attitudes and behaviors of residents will play a key role. The most important thing for residents to participate in MHW separation is to reflect the right to know the MHW separation information. As for the disclosure of MHW separation information, there are still some deficiencies in China, such as insufficient degree of disclosure, low intensity, and single means and ways for residents to understand MHW separation information. This requires the government to establish and improve the whole-process participation mechanism, disclose more information about MHW separation, especially to give residents more rights to know, enrich the channels for information disclosure, and expand the ways in which residents can obtain information.

Finally, the results of this study imply that the government's regulation intensity and regulation capabilities play an important role in the effectiveness of the MHW separation policy. Therefore, the government should improve its regulatory capabilities, including strengthening the construction of an information platform, building a full information supervision platform covering classified transportation, classified transfer to end disposal, improving supervision technology, and increasing supervision frequency. It is worth noting that since the outbreak of COVID-19, the increase in MHW has shown the following two characteristics: First, there is a sharp increase in medical waste, such as used masks, gloves, protective clothing, goggles, and household waste produced by residents' families with fever symptoms. The second is the increase of household kitchen waste. The public responds to the call to stay at home. During this period, daily life, home office, and three meals a day will generate a lot of waste, which adds a lot of burden to the waste cleaning work [55]. All these have brought challenges to the government's MHW regulation capabilities [56]. The government should introduce waste mask disposal methods, strengthen the education and publicity of MHW separation, and increase the facilities for MHW treatment during the pandemic. For example, the government can consider placing special garbage bins for discarded masks in streets and communities.

Author Contributions: Conceptualization, X.W.; data curation, X.W. formal analysis, X.W., L.Z. and Y.C.; methodology, X.W., J.H. and W.Q.; software, X.W.; validation, X.W. and Y.C.; writing-original draft, X.W.; writing-review and editing, X.W., L.Z. and J.H.; visualization, X.W., W.L. and W.Q.; supervision, W.L. All authors have read and agreed to the published version of the manuscript.

Funding: This research was supported by the School of Economics and Trade of Fujian Jiangxia University (00140188).

Institutional Review Board Statement: Not applicable.

Informed Consent Statement: Not applicable.

Data Availability Statement: The data reported in this study is contained within the article.

Conflicts of Interest: The authors declare no conflict of interest.

\section{References}

1. Zhu, Z.; Zhao, Y.; Zhu, Y.; Zhang, M.; Yu, Y.; Guo, Y.; Zhou, T. Efficient treatment of mature landfill leachate with a novel composite biological trickle reactor developed using refractory domestic waste and aged refuse. J. Clean. Prod. 2021, 305, 127194. [CrossRef]

2. Zhang, B.; Lai, K.H.; Wang, B.; Wang, Z. From intention to action: How do personal attitudes, facilities accessibility, and government stimulus matter for household waste sorting? J. Environ. Manag. 2019, 233, 447-458. [CrossRef]

3. Li, L.; Yue, G.; Xinquan, G.; Yingmei, Y.; Hua, C.; Jianping, H.; Jian, Z. Exploring the residents' intention to separate MHW in Beijing and understanding the reasons: An explanation by extended VBN theory. Sustain. Cities Soc. 2018, 37, 637-648. [CrossRef]

4. Casado, R.R.; Rivera, J.A.; García, E.B.; Cuadrado, R.E.; Llorente, M.F.; Sevillano, R.B.; Delgado, A.P. Classification and characterisation of SRF produced from different flows of processed MHW in the Navarra region and its co-combustion performance with olive tree pruning residues. Waste Manag. 2016, 47, 206-216. [CrossRef]

5. Pedersen, J.T.S.; Manhice, H. The hidden dynamics of household waste separation: An anthropological analysis of user commitment, barriers, and the gaps between a waste system and its users. J. Clean. Prod. 2020, 242, 116285. [CrossRef]

6. Chen, L.; Gao, M. A new learning interaction rule for municipal household waste classification behavior based on multi-agentbased simulation. J. Clean. Prod. 2020, 271, 122654. [CrossRef] 
7. Chen, F.; Chen, H.; Guo, D.; Han, S.; Long, R. How to achieve a cooperative mechanism of MHW source separation among individuals-An analysis based on evolutionary game theory. J. Clean. Prod. 2018, 195, 521-531. [CrossRef]

8. Wang, H.; Liu, X.; Wang, N.; Zhang, K.; Matsushita, M. Key factors influencing public awareness of household solid waste recycling in urban areas of china: A case study. Resour. Conserv. Recycl. 2020, 158, 104813. [CrossRef]

9. Chu, Z.; Wang, W.; Wang, B.; Zhuang, J. Research on factors influencing municipal household household waste separate collection: Bayesian belief networks. Sustainability 2020, 8, 152. [CrossRef]

10. Tong, X.; Tao, D. The rise and fall of a "waste city" in the construction of an "urban circular economic system": The changing landscape of waste in Beijing. Resour. Conserv. Recycl. 2016, 107, 10-17. [CrossRef]

11. Ajzen, I. From intentions to actions: A theory of planned behavior. In Action Control; Springer: Berlin/Heidelberg, Germany, 1985; pp. 11-39.

12. Park, J.; Ha, S. Understanding consumer recycling behavior: Combining the theory of planned behavior and the norm activation model. Fam. Consum. Sci. Res. J. 2014, 42, 278-291. [CrossRef]

13. Matthies, E.; Selge, S.; Klöckner, C.A. The role of parental behaviour for the development of behaviour specific environmental norms-The example of recycling and re-use behaviour. J. Environ. Psychol. 2012, 32, 277-284. [CrossRef]

14. Soltani, A.; Sadiq, R.; Hewage, K. Selecting sustainable waste-to-energy technologies for municipal solid waste treatment: A game theory approach for group decision-making. J. Clean. Prod. 2016, 113, 388-399. [CrossRef]

15. KarimGhani, W.A.W.A.; Rusli, I.F.; Biak, D.R.A.; Idris, A. An application of the theory of planned behaviour to study the influencingm factors of participation in source separation of food waste. Waste Manag. 2013, 33, 1276-1281. [CrossRef] [PubMed]

16. Lakhan, C. Evaluating the effects of unit based waste disposal schemes on the collection of household recyclables in Ontario, Canada. Resour. Conserv. Recycl. 2015, 95, 38-45. [CrossRef]

17. Nguyen, T.T.P.; Zhu, D.; Le, N.P. Factors influencing waste separation intention of residential households in a developing country: Evidence from Hanoi. Vietnam. Habitat Int. 2015, 48, 169-176. [CrossRef]

18. Oztekin, C.; Teksz, G.; Pamuk, S.; Sahin, E.; Kilic, D.S. Gender perspective on the factors predicting recycling behavior: Implications from the theory of planned behavior. Waste Manag. 2017, 62, 290-302. [CrossRef]

19. Ofstad, S.P.; Tobolova, M.; Nayum, A.; Klockner, C.A. Understanding the mechanisms behind changing people's recycling behavior at work by applying a comprehensive action determination model. Sustainability 2017, 9, 204. [CrossRef]

20. Zheng, J.; Ma, G.; Wei, J.; Wei, W.; He, Y.; Jiao, Y.; Han, X. Evolutionary process of household waste separation behavior based on social networks. Resour. Conserv. Recycl. 2020, 161, 105009. [CrossRef]

21. Morone, P.; Caferra, R.; Adamo, I.D.; Marcello, P.; Imbert, E.; Morone, A. Consumer willingness to pay for bio-based products: Do certifications matter? Int. J. Prod. Econ. 2021, 240, 108248. [CrossRef]

22. Kohlbacher, J.; Reeger, U.; Schnell, P. Place attachment and social ties emigrants and natives in three urban settings in Vienna. Popul. Space Place 2015, 21, 446-462. [CrossRef]

23. Hargreaves, T. Interacting for the environment: Engaging goffman in pro-environmental action. Soc. Nat. Resour. 2016, $29,53-67$. [CrossRef]

24. Barnes, M.L.; Lynham, J.; Kalberg, K.; Leung, P. Social networks and environmental outcomes. Proc. Natl. Acad. Sci. USA 2016, 113, 6466-6471. [CrossRef]

25. Czajkowski, M.; Hanley, N.; Nyborg, K. Social norms, morals and self-interest as determinants of pro-environment behaviours: The case of household recycling. Res. Econ. 2017, 66, 647-670. [CrossRef]

26. Pei, Z.J. Roles of neighborhood ties, community attachment and local identity in residents' household waste recycling intention. J. Clean. Prod. 2019, 241, 118217. [CrossRef]

27. Matsumoto, S. The opportunity cost of pro-environmental activities: Separating time to promote the environment or earning more money? J. Fam. Econ. 2014, 35, 119-130. [CrossRef]

28. Meng, X.; Wen, Z.; Qian, Y. Multi-agent based simulation for household solid waste recycling behavior Multi-agent based simulation for household solid waste recycling behavior. Resour. Conserv. Recycl. 2018, 128, 535-545. [CrossRef]

29. Long, R.; Yang, J.; Chen, H.; Li, Q.; Fang, W.; Wang, L. Co-evolutionary simulation study of multiple stakeholders in the take-out waste recycling industry chain. J. Environ. Manag. 2019, 231, 701-713. [CrossRef]

30. Escario, J.; Rodriguez-Sanchez, C.; Casaló, L.V. The influence of environmental attitudes and perceived effectiveness on recycling, reducing, and reusing packaging materials in Spain. Waste Manag. 2020, 113, 251-260. [CrossRef]

31. Chen, L.; Gao, M. Novel information interaction rule for municipal household waste classification behavior based on an evolving scale-free network. Resour. Conserv. Recycl. 2021, 168, 105445. [CrossRef]

32. Cohen, J.; Gil, J. An entity-relationship model of the flow of waste and resources in city-regions: Improving knowledge management for the circular economy. Resour. Conserv. Recycl. Adv. 2021, 12, 200058.

33. Alidoosti, Z.; Sadegheih, A.; Govindan, K.; Pishvaee, M.S.; Mostafaeipour, A.; Hossain, A.K. Social sustainability of treatment technologies for bioenergy generation from the municipal solid waste using best worst method. J. Clean. Prod. 2021, $288,125592$. [CrossRef]

34. Meng, X.; Tan, X.; Wang, Y.; Wen, Z.; Tao, Y.; Qian, Y. Investigation on decision-making mechanism of residents' household household waste classification and recycling behaviors. Resour. Conserv. Recycl. 2019, 140, 224-234. [CrossRef]

35. Mukherji, S.B.; Sekiyama, M.; Mino, T.; Chaturvedi, B. Resident knowledge and willingness to engage in waste management in Delhi, India. Sustainability 2016, 8, 1065. [CrossRef] 
36. Han, Z.; Zeng, D.; Li, Q.; Cheng, C.; Shi, G.; Mou, Z. Public willingness to pay and participate in domestic waste management in rural areas of China. Resour. Conserv. Recycl. 2019, 140, 166-174. [CrossRef]

37. Anastasopoulos, N.P.; Anastasopoulos, M.P. The evolutionary dynamics of audit. Eur. J. Oper. Res. 2012, 216, 469-476. [CrossRef]

38. Chen, W.; Hu, Z.H. Using evolutionary game theory to study governments and manufacturers' behavioral strategies under various carbon taxes and subsidies. J. Clean. Prod. 2018, 201, 123-141. [CrossRef]

39. Rocha, A.S.; Salomão, G.M. Environmental policy regulation and corporate compliance in evolutionary game models with well-mixed and structured populations. Eur. J. Oper. Res. 2019, 279, 486-501. [CrossRef]

40. Shen, J.; Gao, X.; He, W.; Sun, F.; Zhang, Z.; Kong, Y.; Wan, Z.; Zhang, X.; Li, Z.; Wang, J.; et al. Prospect theory in an evolutionary game: Construction of watershed ecological compensation system in Taihu Lake Basin. J. Clean. Prod. 2021, 291, 125929. [CrossRef]

41. Shen, H.; Peng, Y.; Guo, C. Analysis of the evolution game of construction and demolition waste recycling behavior based on prospect theory under environmental regulation. Int. J. Environ. Res. Public Health 2018, 15, 1518. [CrossRef]

42. Wang, Z.; Wang, Q.; Chen, B.; Wang, Y. Evolutionary game analysis on behavioral strategies of multiple stakeholders in e-waste recycling industry. Resour. Conserv. Recycl. 2020, 155, 104618. [CrossRef]

43. Smith, J.; Price, G. The logic of animal conflict. Nature 1973, 246, 15-18. [CrossRef]

44. Taylor, P.D.; Jonker, L. Evolutionary stable strategies and game dynamics. Math. Biosci. 1978, 40, 145-156. [CrossRef]

45. $\mathrm{Xu}, \mathrm{J} . ; \mathrm{Xu}, \mathrm{Y}$. Low-carbon technology innovation diffusion under environmental regulation-evolutionary game analysis based on propect theory. Syst. Engine 2015, 33, 118-125.

46. Friedman, D. Evolutionary games in economics. Econometrica 1991, 59, 637-666. [CrossRef]

47. Tang, Y.; Zhang, Q.; Li, Y.; Li, H.; Pan, X.; Mclellan, B. The social-economic-environmental impacts of recycling retired EV batteries under reward-penalty mechanism. Appl. Energy 2020, 251, 113313. [CrossRef]

48. Acuff, K.; Kaffine, D.T. Greenhouse gas emissions, waste and recycling policy. J. Environ. Econ. Manag. 2013, 65, 74-86. [CrossRef]

49. Xu, L.; Ling, M.; Lu, Y.; Shen, M. External influences on forming residents' waste separation behaviour: Evidence from households in Hangzhou, China. Habitat Int. 2017, 63, 21-33. [CrossRef]

50. Wan, C.; Shen, G.Q.; Yu, A. Key determinants of willingness to support policy measures on recycling: A case study in Hong Kong. Environ. Sci. Pol. 2015, 54, 409-418. [CrossRef]

51. Mo, H.; Wen, Z.; Chen, J. China's recyclable resources recycling system and policy: A case study in Suzhou. Resour. Conserv. Recycl. 2009, 53, 409-419. [CrossRef]

52. Wang, Z.; Dong, X.; Yin, J. Antecedents of urban residents' separate collection intentions for household solid waste and their willingness to pay: Evidence from China. J. Clean. Prod. 2018, 173, 256-264. [CrossRef]

53. Agovino, M.; Cerciello, M.; Musella, G. The effects of neighbour influence and cultural consumption on separate waste collection. Theoretical framework and empirical investigation. Ecol. Econ. 2019, 166, 106440.

54. Guerrero, L.A.; Maas, G.; Hogland, W. Solid waste management challenges for cities in developing countries. Waste Manag. 2013, 33, 220-232. [CrossRef] [PubMed]

55. Hassan, M.F.; Shareefdeen, Z. Recent Developments in Sustainable Management of Healthcare Waste and Treatment Technologies. 2021, p. 1090384. Available online: https://www.researchgate.net/profile/Muhammad-Faheem-Hassan/publication/34830223 1_Recent_Developments_in_Sustainable_Management_of_Healthcare_Waste_and_Treatment_Technologies/links/600b2fa7a6 fdccdcb872d676/Recent-Developments-in-Sustainable-Management-of-Healthcare-Waste-and-Treatment-Technologies.pdf (accessed on 10 October 2021).

56. Kulkarni, B.; Anantharama, V. Repercussions of COVID-19 pandemic on municipal solid waste management: Challenges and opportunities. Sci. Total Environ. 2021, 743, 140693. [CrossRef] [PubMed] 